\title{
Efficacy of reduced dose melphalan conditioning for multiple myeloma patients undergoing autologous stem cell transplantation: in the era of combined induction with novel agents
}

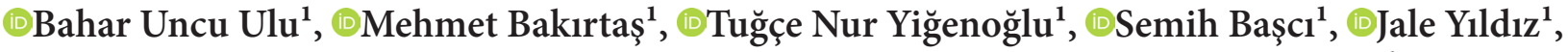

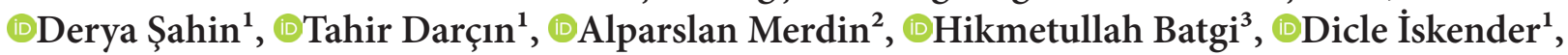 \\ @Nuran Ahu Baysal ${ }^{1}$, ๑Mehmet Sinan Dal ${ }^{1}$, ๑Merih Kızıl Çakar ${ }^{1}$, ๑Fevzi Altuntaş ${ }^{1}$ \\ ${ }^{1}$ University of Health Sciences, Ankara Dr. Abdurrahman Yurtaslan Oncology Training and Research Hospital, Department of Hematology \\ and Bone Marrow Transplantation Center, Ankara, Turkey \\ ${ }^{2}$ University of Health Sciences, Ankara Gülhane Training and Research Hospital, Department of Hematology and Bone Marrow \\ Transplantation Center, Ankara, Turkey \\ ${ }^{3}$ Ankara Training and Research Hospital, Department of Hematology, Ankara, Turkey
}

Cite this article as: Uncu Ulu B, Bakırtaş M, Yiğenoğlu TN, et al. Efficacy of reduced dose melphalan conditioning for multiple myeloma patients undergoing autologous stem cell transplantation: in the era of combined induction with novel agents. J Health Sci Med 2021; 4(2): $203-208$.

\begin{abstract}
Aim: Melphalan $200 \mathrm{mg} / \mathrm{m}^{2}$ (MEL 200) is known as the standard conditioning regimen for Multiple Myeloma (MM) patients in autologous stem cell transplantation (ASCT). Most of the studies showing the superiority of MEL 200 versus melphalan 140 $\mathrm{mg} / \mathrm{m}^{2}$ (MEL 140) were performed in the era of conventional chemotherapies. However, today, several novel agents such as proteasome inhibitors, immunomodulatory agents have been introduced in MM treatment algorithms. There is limited data on the impact of this dose reduction on progression-free survival (PFS) or overall survival (OS). The present study compares MEL 140 and MEL 200 conditioning for ASCT in patients treated with combination therapy of bortezomib-containing induction.

Material and Method: Results of 84 MM patients who underwent ASCT at our center between 2010 and 2018 were analyzed retrospectively.

Results: In the MEL 140 group, PFS was 9 months (95\% CI 2.2-15.8) and OS was 30 months (95\% CI 9.5-50.4), while PFS was 13 months (95\% CI 10.5-15.5) and OS was 34 months (95\% CI 6.9-61) in the MEL 200 group. There was no statistically significant difference in PFS and OS between the two groups (p:0.6, p:0.7).

Conclusion: Consequently, MEL 140 and MEL 200 were found similar in terms of engraftment duration, transplant-related mortality rate, and survival rates. The idea that similar outcomes in both MEL 140 and MEL 200 group in patients who received combined induction treatment with novel agent suggested that MEL 140 may be used more commonly than the standard approach of MEL 200.
\end{abstract}

Keywords: Melphalan, autologous stem cell transplantation, multiple myeloma

\section{INTRODUCTION}

For more than 20 years, autologous hematopoietic stem cell transplantation (ASCT) after high-dose chemotherapy has been the standard consolidation therapy for newly diagnosed, fit multiple myeloma (MM) patients. High-dose chemotherapy following ASCT is superior to conventional chemotherapy in MM patients $(1,2)$. After high-dose chemotherapy following induction with novel treatment approaches such as thalidomide analogs and proteasome inhibitors, the benefit of ASCT has been confirmed (35). Compared to conventional chemotherapies, ASCT provides the patient advantages in progression-free survival (PFS) and overall survival (OS) (2,4). ASCT is also widely administered in elderly, fit MM patients $(6,7)$. Furthermore, some studies also show the superiority of ASCT versus conventional chemotherapy in elderly patients $(7,8)$. In these studies, patients were administered high-dose chemotherapy with the dose of $200 \mathrm{mg} / \mathrm{m}^{2}$ melphalan (MEL 200) (1-4). MEL 200 was found to be less toxic than other high-dose combination regimens $(9,10)$. For this reason, MEL 200 has been accepted as the standard conditioning regimen for ASCT and remains widely used in current practice $(11,12)$. Otherwise, some studies with 
MEL 200 related increased toxicity in elderly patients and those with renal failure (13-15). Organ dysfunction and decreased drug metabolism have been considered causes of increased melphalan toxicity in elderly MM patients. As a result, the dose of $140 \mathrm{mg} / \mathrm{m}^{2}$ Melphalan (MEL 140) is widely preferred in elderly patients and patients with renal failure in clinical practice (15-19). However, in studies comparing MEL 140 and MEL 200, MEL 140 was associated with lower response rates and shorter survival than MEL 200 (17-20). There is limited data on the impact of reduced dose reduction on progression-free survival (PFS) or overall survival (OS) in the era of induction with novel agents. This study aims to compare the efficacy of the dose of conditioning regimen as melphalan $140 \mathrm{mg} /$ $\mathrm{m}^{2}$ or $200 \mathrm{mg} / \mathrm{m}^{2}$ in terms of the effect on survival and transplantation response in MM patients who received a bortezomib-containing combination as induction therapy at our center.

\section{MATERIAL AND METHOD}

This study was approved by the local human research ethics committee. All procedures performed in studies involving human participants were in accordance with the ethical standards of the institutional and/or national research committee and with the 1964 Helsinki declaration and its later amendments or comparable ethical standards. The study was carried out with the permission of Dr. Abdurrahman Yurtaslan Oncology Training and Research Hospital Ethics Committee (date: 06.11.2019, decision no: 2019-11/421).

The results of 84 multiple myeloma patients who underwent ASCT following induction therapy between 2010 and 2018 at Dr. Abdurrahman Yurtaslan Oncology Training and Research Hospital Bone Marrow Transplantation Center were analyzed retrospectively. Patients' age, gender, myeloma subgroup, disease stage, number of treatments they received before transplantation, history of radiotherapy, presence of renal failure, the melphalan dose they received, the quantity of CD 34+ infused, and disease status before transplantation were recorded. The International Staging System (ISS) calculated from serum $\beta_{2}$-microglobulin and albumin levels at the time of diagnosis was used for risk classification (21). Patients treated with bortezomib-containing combination treatments in induction therapy were enrolled in the study, while patients who received non-bortezomib induction treatment were excluded. Patients with tandem transplants, defined as second transplantation performed within six months without progression or recurrence after the first ASCT, were not included in the study. OS was defined as the time from transplantation to death or the last follow-up date for those who survived. PFS was defined as the time from transplantation to the date of disease progression or death (whichever occurs earlier) or the last follow-up date for those without death or disease progression. Transplantrelated mortality (TRM) was defined as death within the first 100 days after ASCT. Assessment of treatment response was performed according to the guidelines from the International Multiple Myeloma Working Group (IMWG) guidelines (22). Patients were stratified into two groups according to the dose of conditioning regimen they received, i.e., $140 \mathrm{mg} / \mathrm{m}^{2}$ melphalan (MEL140) or $200 \mathrm{mg} / \mathrm{m}^{2}$ melphalan (MEL200). Patients receiving doses other than these were not included in the study. MEL140 was administered for those over 70 years old and/or with serum creatinine levels equal to or higher than $2 \mathrm{mg} / \mathrm{dL}$. In contrast, MEL 200 was administered as the conditioning regimen for the other patients. Glomerular filtration rates (GFRs) of patients were calculated with chronic kidney disease epidemiology collaboration (CKD-EPI) equation using plasma creatinine, age, gender, and race variables (23). The renal function evaluation was performed by stratifying glomerular filtration rate (GFR) into two groups as $>50 \mathrm{~mL} / \mathrm{min}$ and $\leq 50 \mathrm{~mL} / \mathrm{min}$. Engraftment definition; for neutrophils, it was defined as the first day of absolute neutrophil count (ANC) $>500 / \mathrm{mm}^{3}$ or $1000 /$ $\mathrm{mm}^{3}$ for three consecutive days. It was defined as the first day of thrombocytes $>20000 / \mathrm{mm}^{3}$ for three consecutive days without transfusion for thrombocytes.

\section{Statistical Analysis}

All statistical analyses were performed with the SPSS V21.0 (SPSS Inc., Chicago, IL) program. Descriptive statistics were used to summarize the data. Categorical data were presented as ratios and numerical data as median and mean \pm standard deviation. The chi-square test was used for categorical data and the Kruskal Wallis test for numerical data in comparing the groups. Kaplan-Meier was used for PFS and OS, and log-rank tests were used for confounding factors. $P$ values of $\leq 0.05$ were considered statistically significant.

\section{RESULTS}

Of the 84 patients, 21 patients (25\%) were enrolled in the MEL 140 group, and the median age was 61 years (41$72)$ in patients. $63(75 \%)$ patients were in the MEL 200 group, and the median age was 57 years (36-66) in this group. The clinical characteristics of patients are given in Table 1. MEL 200 and MEL 140 groups were similar in the myeloma subgroup and ISS staging $(\mathrm{p}=0.1, \mathrm{p}=0.35$, respectively). GFR was $\leq 50 \mathrm{~mL} / \mathrm{min}$ in (14\%) patients in the MEL 140 group and $\leq 50 \mathrm{~mL} / \mathrm{min}$ in two $(3.4 \%)$ patients in the MEL 200 group. In both MEL 140 and MEL 200 groups, neutrophil engraftment occurred on a median Day 11 (9-21 days in the MEL 140 group, 9-14 days in the MEL 200 group), and thrombocyte engraftment occurred on a median Day 12 (10-23 days in the MEL 140 group, 7-24 days in the MEL 200 group). 


\begin{tabular}{|c|c|}
\hline & $\begin{array}{l}\text { Patient Population (n), } \\
\text { Median (range) }\end{array}$ \\
\hline Age (years) & $58(36-72)$ \\
\hline Gender (number) & Female/Male: $33 / 51$ \\
\hline $\begin{array}{l}\text { Multiple myeloma } \\
\text { subgroup }(\mathrm{n})\end{array}$ & $\begin{array}{l}\text { Heavy chain: } 70 \\
\text { Light chain: } 13 \\
\text { Non-secretory: } 1\end{array}$ \\
\hline $\begin{array}{l}\text { International Staging } \\
\text { System (ISS) stage (n) }\end{array}$ & $\begin{array}{c}\text { ISS I: } 19 \\
\text { ISS II: } 26 \\
\text { ISS III: } 24 \\
\text { Not Evaluated: } 15\end{array}$ \\
\hline Durie Salmon stage (n) & $\begin{array}{c}\text { DS1: } 6 \\
\text { DS2: } 8 \\
\text { DS3: } 66 \\
\text { Not Evaluated: } 4\end{array}$ \\
\hline $\begin{array}{l}\text { Disease status before } \\
\text { transplantation }(\mathrm{n})\end{array}$ & $\begin{array}{c}\text { CR: } 27 \\
\text { VGPR: } 22 \\
\text { PR: } 22 \\
\text { Stable: } 8 \\
\text { Refractory: } 2 \\
\text { Not evaluated: } 3\end{array}$ \\
\hline Melphalan dose (n) & $\begin{array}{l}140 \mathrm{mg} / \mathrm{m}^{2}: 21 \\
200 \mathrm{mg} / \mathrm{m}^{2}: 63\end{array}$ \\
\hline $\begin{array}{l}\text { Renal failure }(\mathrm{GFR}) * \\
\text { (n) }\end{array}$ & $\begin{array}{l}\text { GFR }>50 \mathrm{~mL} / \mathrm{min}: 79 \\
\text { GFR } \leq 50 \mathrm{~mL} / \mathrm{min}: 5\end{array}$ \\
\hline $\begin{array}{l}\text { Number of chemotherapy } \\
\text { courses } \\
\text { (n) }\end{array}$ & $\begin{array}{l}1: 23 \\
2: 44 \\
3: 13 \\
4: 2 \\
5: 1\end{array}$ \\
\hline History of radiotherapy (n) & Yes/No: $10 / 74$ \\
\hline $\begin{array}{l}\text { Quantity of CD34+ infused } \\
\text { (median) }\end{array}$ & $4.54 \times 10^{6} / \mathrm{kg}(2.3-9.1)$ \\
\hline
\end{tabular}

Patients were stratified into subgroups according to disease status at the time of transplantation (complete response (CR), very good partial response (VGPR), partial response (PR), stable disease, progressive disease). There was no statistically significant difference between MEL 140 and MEL 200 in PFS and OS according to disease status before transplantation $(\mathrm{p}=0.3 ; \mathrm{p}=0.7$, respectively) (Table 2 ).

When the patients were grouped as those under 60 years of age and 60 years and above, there was no statistically significant difference between MEL 140 and MEL 200 conditioning regimens in PFS and OS ( $p=0.9$; $\mathrm{p}=0.5$, respectively). When GFR was stratified into two groups as $>50 \mathrm{~mL} / \mathrm{min}$ and $\leq 50 \mathrm{~mL} / \mathrm{min}$, there was no statistically significant difference between MEL 140 and MEL 200 conditioning regimes in terms of PFS ( $p=0.7$ ) (Table 3).

In the MEL 140 group, PFS was nine months (95\% CI 2.2-15.8) and OS was 30 months (95\% CI 9.5-50.4), while PFS was 13 months (95\% CI 10.5-15.5) and OS was 34 months (95\% CI 6.9-61) in the MEL 200 group. There was no statistically significant difference in PFS and OS between the two groups ( $\mathrm{p}=0.6, \mathrm{p}=0.7$, respectively) (Figures 1 and 2). None TRM was observed in both groups.

Collaboration equation.

Table 3. PFS and OS in Melphalan 140 and Melphalan 200 arms according to age group and renal failure stage

\begin{tabular}{|c|c|c|c|c|c|c|c|}
\hline Age group & MEL 140 (n) & $\begin{array}{c}\text { PFS (months) } \\
95 \% \text { CI }\end{array}$ & OS (months) $95 \% \mathrm{CI}$ & MEL 200 (n) & $\begin{array}{c}\text { PFS (months) } \\
95 \% \mathrm{CI}\end{array}$ & $\begin{array}{c}\text { OS (months) } \\
95 \% \text { CI }\end{array}$ & $p$ value \\
\hline$<60$ years & 9 & $\begin{array}{c}7 \\
(1.9-12.1)\end{array}$ & $\begin{array}{c}23 \\
(7,6-38,4)\end{array}$ & 38 & $\begin{array}{c}14 \\
(0.6-27.4)\end{array}$ & $\begin{array}{c}42 \\
(13.8-70.2)\end{array}$ & $\mathrm{p}=0.5(\mathrm{OS})$ \\
\hline$\geq 60$ years & 12 & $\begin{array}{c}41 \\
(22.6-59.4) \\
\end{array}$ & 47 & 25 & $\begin{array}{c}12 \\
(6.2-17.8) \\
\end{array}$ & $13(0-41.8)$ & $\mathrm{p}=0.9(\mathrm{PFS})$ \\
\hline GFR (ml/min) & MEL 140 (n) & $\begin{array}{c}\text { PFS (months) } \\
95 \% \mathrm{CI}\end{array}$ & OS (months) 95\% CI & MEL 200 (n) & $\begin{array}{c}\text { PFS (months) } \\
95 \% \text { CI }\end{array}$ & $\begin{array}{c}\text { OS (months) } \\
95 \% \mathrm{CI}\end{array}$ & $p$ value \\
\hline$\geq 50 \mathrm{ml} / \mathrm{min}$ & 18 & $\begin{array}{c}9 \\
(6.1-11.9)\end{array}$ & $17(0-35)$ & 61 & $\begin{array}{c}13 \\
(10.1-15.8)\end{array}$ & $\begin{array}{c}34 \\
(8.4-59.5)\end{array}$ & $\begin{array}{c}\mathrm{N} / \mathrm{A}(\mathrm{OS}) \\
\mathrm{p}=0.7(\mathrm{PFS})\end{array}$ \\
\hline$<50 \mathrm{ml} / \mathrm{min}$ & 3 & 7 & 30 & 2 & 12 & - & \\
\hline
\end{tabular}

Table 2. PFS and OS in Melphalan 140 and Melphalan 200 arms according to the disease status before transplant

\begin{tabular}{|c|c|c|c|c|c|c|c|}
\hline $\begin{array}{l}\text { Disease status before } \\
\text { transplant }\end{array}$ & $\operatorname{MEL140}(n)$ & $\begin{array}{c}\text { PFS (months) } \\
95 \% \text { CI }\end{array}$ & $\begin{array}{l}\text { OS (months) } \\
95 \% \mathrm{CI}\end{array}$ & $\operatorname{MEL200}(\mathbf{n})$ & $\begin{array}{c}\text { PFS (months) } \\
95 \% \text { CI }\end{array}$ & $\begin{array}{l}\text { OS (months) } \\
95 \% \mathrm{CI}\end{array}$ & p-value \\
\hline Complete remission & 6 & $\begin{array}{c}12 \\
(7.2-16.8)\end{array}$ & 23 & 16 & $\begin{array}{c}14 \\
(0-40.3)\end{array}$ & $\begin{array}{c}50 \\
(0-110)\end{array}$ & $\mathrm{p}=0.7(\mathrm{OS})$ \\
\hline Very good partial response & 6 & $\begin{array}{c}20 \\
(0-48.8)\end{array}$ & 31 & 16 & $\begin{array}{c}12 \\
(7.8-16.2)\end{array}$ & $\begin{array}{c}12 \\
(0.2-23.8)\end{array}$ & \\
\hline Partial response & 7 & $\begin{array}{c}8 \\
(0-41.3)\end{array}$ & $\begin{array}{c}30 \\
(0-60.4)\end{array}$ & 15 & $\begin{array}{c}12 \\
(6.3-17.7)\end{array}$ & 34 & $\mathrm{p}=0.3(\mathrm{PFS})$ \\
\hline Stable disease & 2 & 7 & 3 & 6 & 13 & 13 & \\
\hline
\end{tabular}




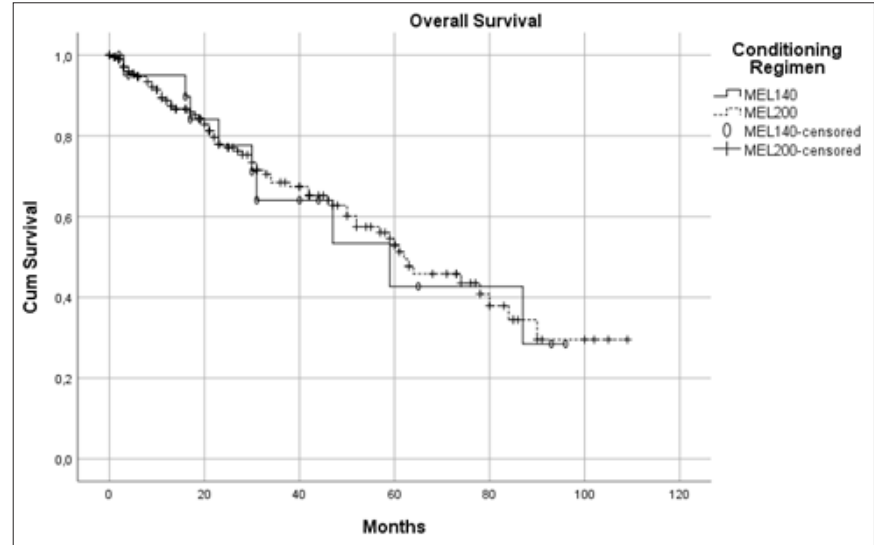

Figure 1. Overall Survival Curve

Abbreviations: Mel 140: Melphalan $140 \mathrm{mg} / \mathrm{m}^{2}$; Mel 200: Melphalan $200 \mathrm{mg} / \mathrm{m}^{2}$

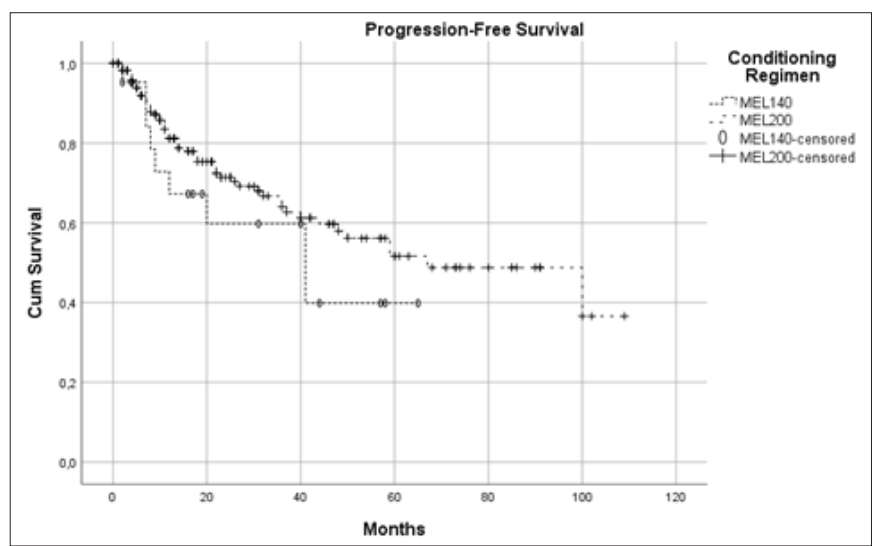

Figure 2. Progression Free Survival Curve

Abbreviations: Mel 140: Melphalan $140 \mathrm{mg} / \mathrm{m}^{2}$; Mel 200: Melphalan $200 \mathrm{mg} / \mathrm{m}^{2}$

\section{DISCUSSION}

The data about the studies showing the superiority of MEL 200 over MEL 140 for the conditioning regimen of ASCT in the multiple myeloma patients were performed in the era of conventional chemotherapies. Currently, several novel agents such as proteasome inhibitors, immunomodulatory drugs, monoclonal antibodies have been included in the treatment of MM. The lack of significant difference in OS and PFS between MEL 140 and MEL 200 in patients who received combination therapies containing novel agents for induction therapy has led to the idea that MEL 140 may be used more widely than the standard approach, MEL 200.

In the CALM study conducted by Auner et al. (19) MEL 200 was superior to MEL 140 in terms of OS, PFS, and relapse risk in patients with a response rate less than the partial response at transplantation time. This result has been explained by the higher dose dependence of melphalan-induced anti-myeloma effects in cells with limited chemosensitivity. However, the study's conclusions also support that MEL 140 may be more administered versus MEL 200 due to the disease response of VGPR/CR before the ASCT and raise the question of whether more patients should receive MEL 140 (19).
This question becomes essential considering that novel combined induction regimens provide higher rates of VGPR/CR. Therefore, the remission status of MM before the first ASCT should be taken into account when deciding the melphalan dose (19). In our study, when patients were stratified into subgroups according to their disease status at the time of transplantation, there was no statistically significant difference between MEL 140 and MEL 200 in terms of PFS and OS according to the disease response before transplantation suggesting that MEL 140 may be preferred since it is associated with a lower risk of toxicity in ASCT.

In the same study by Auner et al. (19) the superiority of MEL 200 over MEL 140 could not be demonstrated in patients with high-risk genetic features or higher ISS stages. Similarly, in our study, the superiority of MEL 200 over MEL 140 could not be demonstrated in patients with higher ISS, and Durie Salmon stages at the time of diagnosis. Melphalan $200 \mathrm{mg} / \mathrm{m}^{2}$ is insufficient to overcome poor cytogenetic characteristics and high tumor burden, so that new strategies should be developed for this high-risk group.

In the studies of myeloma patients treated with high-dose melphalan following ASCT, higher dose melphalan exposure has been associated with higher toxicity and also better disease responses $(11,12,24)$. In a recent study, exposure to high-dose melphalan was found to increase overall survival in myeloma patients; however, despite the net survival benefit, there was no association between melphalan exposure and progression-free survival (24). PFS was nine months in our study, and OS was 30 months in the MEL 140 group, while PFS was 13 months, and OS was 34 months in the MEL 200 group. There was no statistically significant difference in PFS and OS between both groups, and survivors were very similar. Similarly, in the study by Katragad et al. (16) there was no difference between MEL 140 and MEL 200 arms in PFS and OS. In the study conducted by Badros et al. (13) there was an improvement in event-free survival with MEL 200 compared to MEL 140; however, they did not report any OS progress.

In a recent The Center For International Blood and Marrow Transplant Research (CIBMTR) analysis of elderly patients undergoing ASCT for MM, examined the effect of the MEL conditioning dose (25). One thousand two hundred twenty-three patients received reduced dose (MEL140) conditioning, whereas 868 patients received a standard dose in patients $\geq 70$ years. The analysis focused on the patients aged $\geq 70$ years, at a dose of MEL 200 was associated with superior PFS and OS and a lower rate of non-relapse mortality rate compared with MEL 140 (25). The authors discussed that sicker patients were expected to have more complications and TRM. They underlined 
that without understanding the reason for choosing Mel 140 vs. Mel 200 beyond performance status and comorbidity score, it was not possible to recommend Mel 200 in the elderly group. The results of CIBMTR analysis provided MEL 200 safely in some older adults aged $\geq 70$ years (25). We did not observe the superiority of standarddose melphalan in our cohort; the lower patients number included is a significant limitation of our study. Rather than age, evaluating the patients' comorbidities and performance regarding geriatric assessments are more critical points when deciding on conditioning.

While some studies suggest that renal failure may be associated with the excess toxicity of MEL 200, others have not reported such association (15-17,20,26). In our study, GFR was stratified into two groups as $>50 \mathrm{~mL} / \mathrm{min}$ and $\leq 50 \mathrm{~mL} / \mathrm{min}$; there was no statistically significant difference between melphalan doses. A study conducted by Badros et al. (14) demonstrated better tolerability with MEL 140 than MEL 200, with similar survival in patients older than 70 years of age. Similarly, we could not demonstrate any difference between MEL 140 and MEL 200 in terms of OS and PFS according to the age (as those under 60 years of age, 60 years and above) current study. In the study by Katragad et al. (16) an increased frequency of prolonged neutropenia and neutropenic fever was observed in patients receiving MEL 140, however, in our study, both in MEL 140 and MEL 200 groups, neutrophil engraftment was observed on a median Day 11, and thrombocyte engraftment was observed on a median Day 12, both with similar frequency.

If Mel 140 becomes more widely used, it will be a more cost-effective treatment option, predicting that the lower doses of melphalan will reduce ASCT costs by $30 \%$. Considering the increased costs associated with novel myeloma treatment modalities, that is predictable to be offset costs by a reduced conditioning regimen like MEL 140.

Unlike other studies, the present study has analyzed data from patients with renal failure or the elderly and data from all patients who received MEL 140 regardless of the cause of dose reduction. Patients who had only one ASCT were analyzed, thus minimizing the confounding effect of a second ASCT or tandem transplantation. However, due to MEL 200 as the standard dose in our clinic and dose reduction is performed just when required clinically for limited number of patients in the MEL 140 group.

\section{CONCLUSION}

Melphalan 140 and MEL 200 were found similar in terms of engraftment duration, transplant-related mortality rate, and survival rates in patients who received combination treatment with new agents in induction therapy. Reduced dose melphalan (MEL140) may replace the standard dose melphalan in the group of patients who do not meet high-risk criteria during the era of novel induction agents and those who undergo transplantation with complete response or very good partial response. On the other hand, more extensive studies are warranted for MEL 140 to replace MEL 200 in patients with normal renal function and young patients.

\section{ETHICAL DECLARATIONS}

Ethics Committee Approval: The study was carried out with the permission of Dr. Abdurrahman Yurtaslan Oncology Training and Research Hospital Ethics Committee (date: 06.11.2019, decision no: 201911/421).

Informed Consent: Because the study was designed retrospectively, no written informed consent form was obtained from patients.

Referee Evaluation Process: Externally peer-reviewed. Conflict of Interest Statement: The authors have no conflicts of interest to declare.

Financial Disclosure: The authors declared that this study has received no financial support.

Author Contributions: All of the authors declare that they have all participated in the design, execution, and analysis of the paper, and that they have approved the final version.

\section{REFERENCES}

1. Attal M, Harousseau JL, Stoppa AM, et al. A prospective, randomized trial of autologous bone marrow transplantation and chemotherapy in multiple myeloma. N Engl J Med 1996; 335: 91-7.

2. Child JA, Morgan GJ, Davies FE, et al. High-dose chemotherapy with hematopoietic stem-cell rescue for multiple myeloma. N Engl J Med 2003; 348: 1875-83.

3. Gay F, Oliva S, Petrucci MT, et al. Chemotherapy plus lenalidomide versus autologous transplantation, followed by lenalidomide plus prednisone versus lenalidomide maintenance, in patients with multiple myeloma: a randomized, multicentre, phase 3 trial. Lancet Oncol 2015; 16: 1617-29.

4. Palumbo A, Cavallo F, Gay F, et al. Autologous transplantation and maintenance therapy in multiple myeloma. N Engl J Med 2014; 371: 895-905.

5. Gay F, Oliva S, Petrucci MT, et al. Autologous transplant vs oral chemotherapy and lenalidomide in newly diagnosed young myeloma patients: a pooled analysis. Leukemia 2017; 31: 1727-34.

6. Costa LJ, Zhang MJ, Zhong X, et al. Trends in utilization and outcomes of autologous transplantation as early therapy for multiple myeloma. Biol Blood Marrow Transplant 2013; 19: 1615-24.

7. Auner HW, Szydlo R, Hoek J, et al. Trends in autologous hematopoietic cell transplantation for multiple myeloma in Europe: Increased use and improved outcomes in elderly patients in recent years. Bone Marrow Transplant 2015; 50: 209-15.

8. Palumbo A, Bringhen S, Petrucci MT, et al. Intermediate-dose melphalan improves survival of myeloma patients aged 50 to 70 : results of a randomized controlled trial. Blood 2004; 104: 3052-7. 
9. Moreau P, Facon T, Attal M, et al. comparison of $200 \mathrm{mg} / \mathrm{m}^{2}$ melphalan and 8 Gy total body irradiation plus $140 \mathrm{mg} / \mathrm{m}^{2}$ melphalan as conditioning regimens for peripheral blood stem cell transplantation in patients with newly diagnosed multiple myeloma: final analysis of the Intergroupe Francophone du Myélome 9502 randomized trial. Blood 2002; 99: 731-5.

10. Lahuerta JJ, Mateos MV, Martínez-López J, et al. Busulfan $12 \mathrm{mg}$ / $\mathrm{kg}$ plus melphalan $140 \mathrm{mg} / \mathrm{m}^{2}$ versus melphalan $200 \mathrm{mg} / \mathrm{m}^{2}$ as conditioning regimens for autologous transplantation in newly diagnosed multiple myeloma patients included in the PETHEMA/ GEM$^{2} 000$ study. Haematologica 2010; 95: 1913-20.

11. Palumbo A, Bringhen S, Bruno B, et al. Melphalan $200 \mathrm{mg} / \mathrm{m}^{2}$ versus melphalan $100 \mathrm{mg} / \mathrm{m}^{2}$ in newly diagnosed myeloma patients: A prospective, multicenter phase 3 study. Blood 2010; 115: 1873-9.

12. Shah N, Callander N, Ganguly S, et al. Hematopoietic stem cell transplantation for multiple myeloma: guidelines from the american society for blood and marrow transplantation. Biol Blood Marrow Transplant 2015; 21: 1155-66.

13. Badros A, Barlogie B, Siegel E, et al. Results of autologous stem cell transplant in multiple myeloma patients with renal failure. $\mathrm{Br} J$ Haematol 2001; 114: 822-9.

14. Badros A, Barlogie B, Siegel E, et al. Autologous stem cell transplantation in elderly multiple myeloma patients over the age of 70 years. Br J Haematol 2001; 114: 600-7.

15. Sweiss K, Patel S, Culos K. Melphalan $200 \mathrm{mg} / \mathrm{m}^{2}$ in patients with renal impairment is associated with increased short-term toxicity but improved response and longer treatment-free survival. Bone Marrow Transplant 2016; 51: 1337-41.

16. Katragadda L, McCullough LM, Dai Y, et al. effect of melphalan $140 \mathrm{mg} / \mathrm{m}^{2}$ vs $200 \mathrm{mg} / \mathrm{m}^{2}$ on toxicities and outcomes in multiple myeloma patients undergoing single autologous stem cell transplantation-a single center experience. Clin Transplant 2016; 30: 894-900.

17. Muchtar E, Dingli D, Kumar S, et al. Autologous stem cell transplant for multiple myeloma patients 70 years or older. Bone Marrow Transplant 2016; 51: 1449-55.

18. Dimopoulos MA, Terpos E, Chanan-Khan A, et al. Renal impairment in patients with multiple myeloma: A consensus statement on behalf of the International Myeloma Working Group. J Clin Oncol 2010; 28: 4976-84.

19. Auner HW, Iacobelli S, Sbianchi G, et al. Melphalan $140 \mathrm{mg} / \mathrm{m}^{2}$ or $200 \mathrm{mg} / \mathrm{m}^{2}$ for autologous transplantation in myeloma: Results from the collaboration to collect autologous transplant outcomes in Lymphoma and Myeloma (CALM) study. A report by the EBMT chronic malignancies working party. Haematologica 2018; 103: 514-21.

20. Garderet L, Beohou E, Caillot DS, et al. Upfront autologous stem cell transplantation for newly diagnosed elderly multiple myeloma patients: A prospective multicenter study. Haematologica 2016 101: 1390-7.

21.Greipp PR, Miguel JS, Dune BGM, et al. International staging system for multiple myeloma. J Clin Oncol 2005; 23: 3412-20.

22. Durie BGM, Harousseau JL, Miguel JS, et al. International uniform response criteria for multiple myeloma. Leukemia 2006; 20: 146773

23. Levey AS, Stevens LA, Schmid $\mathrm{CH}$, et al. A New Equation to Estimate Glomerular Filtration Rate Disclosure conflicts of interest: We have received confirmation from Drs. Ann Intern Med 2009; 150: 604-12.

24. Nath CE, Trotman J, Tiley C, et al. High melphalan exposure is associated with improved overall survival in myeloma patients receiving high dose melphalan and autologous transplantation. $\mathrm{Br}$ Clin Pharmacol 2016; 149-59.

25. Munshi PN, Vesole D, Jurczyszyn A, et al. Age no bar: A CIBMTR analysis of elderly patients undergoing autologous hematopoietic cell transplantation for multiple myeloma. Cancer 2020 Dec 1; 126 5077-87.
26. Auner HW, Garderet L, Kröger N. Autologous haematopoietic cell transplantation in elderly patients with multiple myeloma. $\mathrm{Br} \mathrm{J}$ Haematol 2015; 171: 453-62. 